\title{
AVALIAÇÃO DA QUALIDADE AMBIENTAL URBANA NO MUNICÍPIO DE ALTAMIRA, PARÁ
}

\section{ARTIGO ORIGINAL}

PEIXOTO, Amanda Silva ${ }^{1}$

JESUS, Edmir dos Santos ${ }^{2}$

JUNIOR, Antônio Pereira ${ }^{3}$

PEIXOTO, Amanda Silva. JESUS, Edmir dos Santos. JUNIOR, Antônio Pereira. Avaliação da qualidade ambiental urbana no Município de Altamira, Pará. Revista Científica Multidisciplinar Núcleo do Conhecimento. Ano 04, Ed. 10, Vol. 08, pp. 5476. Outubro de 2019. ISSN: 2448-0959, Link de acesso: https://www.nucleodoconhecimento.com.br/engenharia-ambiental/qualidadeambiental

\section{RESUMO}

Nas cidades da Amazônia, o processo de urbanização tem se dado de forma diversa, contraditória e complementar. O objetivo do trabalho é realizar o levantamento quanto a percepção do meio ambiente que a comunidade possui, bem como utilizar indicadores para efetuar a pesquisa qualiquantitativa, acerca da Qualidade Ambiental Urbana (QAU) no bairro Jardim Independente I, zona sudoeste do município de Altamira-PA. A metodologia utilizada foi a pesquisa-ação exploratória, na avaliação do

\footnotetext{
${ }^{1}$ Engenheira Ambiental.

${ }^{2}$ Doutor em Ciências Climáticas. Universidade do Estado do Pará. Departamento de Engenharia Ambiental.

${ }^{3}$ Mestre em Ciências Ambientais; Especialista em Planejamento e Gerenciamento de Águas; Especialista em Gestão Hídrica e Ambiental; Licenciado Pleno em Ciências Biológicas.
} 
aspecto qualitativo, para verificação da percepção dos indivíduos amostrados, quanto à QAU nesse bairro. Para a obtenção dos dados, foi definida uma amostragem probabilística aleatória simples, $10 \%$ da população do bairro, para a aplicação de 225 formulários mistos (com perguntas abertas e fechadas) aos indivíduos amostrados. Os dados obtidos e analisados indicaram a percepção de quatro problemas ambientais no bairro: falta de pavimentação das vias, saneamento básico, queimadas e escassez de árvores. O valor obtido para o IQAU foi de 36,6, o que classifica a qualidade ambiental urbana como "ruim", no bairro estudado. A conclusão é que a percepção ambiental dos habitantes do bairro Jardim Independente I, não foi dependente do grau de escolaridade, mas sim da visão que possuem sobre qualidade de vida e do ambiente. Além disso, os valores encontrados para o IQAU, indicaram que essa visão, atualmente, está comprometida e desse modo, há a necessidade de ações envolvidas com o gerenciamento urbano, para mitigação dos problemas existentes no bairro.

Palavras-Chave: Indicadores ambientais, percepção ambiental, urbanização.

\section{INTRODUÇÃO}

A urbanização nacional tem-se revelado crescente nas últimas décadas. De acordo com o último censo demográfico, realizado no ano de 2010, a taxa de urbanização do Brasil é de $84,36 \%$, o que corresponde a 160.925 .792 pessoas. O processo de urbanização no Brasil é um fenômeno recente, onde pode-se observar o crescimento da taxa de urbanização a partir de 1940, período em que a população era predominantemente rural (IBGE, 2010; SANTOS, 2009).

Nesse contexto, verifica-se que, nas cidades da Amazônia, o processo de urbanização tem se dado de forma difusa, sobretudo, a partir dos anos 1960/70, em que foram implementados projetos de integração da Amazônia ao território nacional, colonização agrícola e fomento de atividades produtivas ligadas à mineração e à produção energética, associados à expansão do capital na Amazônia, tem como reflexo o crescimento demográfico, particularmente nas cidades que receberam grandes 
empreendimentos econômicos (minerais e energéticos), a exemplo de Canaã dos Carajás, Juruti, Altamira e Vitória do Xingu, no estado do Pará (TRINDADE JÚNIOR, 2015).

De um modo geral, o processo de urbanização apresenta características negativas ao meio ambiente, como o uso e ocupação inadequado do solo, que compromete áreas ambientalmente sensíveis (beira de córregos, mangues, dunas, várzeas e matas), crescimento de favelas e ocupações ilegais, ocorrência de enchentes, devido a impermeabilização do solo, comprometimento dos recursos hídricos e marítimos com a disposição de esgotos, entre outros (MARICATO, 2009). O crescimento populacional do município foi influenciado pela instalação da Usina Hidrelétrica de Belo Monte (UHEBM), na cidade de Vitória do Xingu-Pará, em 2011. E Altamira, por ser polo da região Transamazônica, foi o município que recebeu um maior contingente de pessoas, passando de uma população de 99.075 habitantes, em 2010, para cerca de 109.938 em 2016 (IBGE, 2016b).

Ademais, esse aumento populacional ocasionou o surgimento de novos bairros/loteamentos e a expansão dos bairros já existentes, além de promover uma maior demanda por serviços essenciais (saúde, educação, saneamento básico, segurança pública), o que pode ter comprometido a qualidade ambiental e, por conseguinte, a qualidade de vida dos habitantes. Dessa forma, a área selecionada para o estudo foi o bairro Jardim Independente I (Figura 01), localizado no município

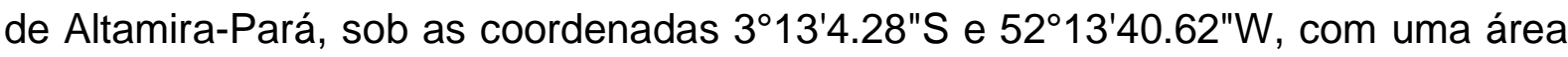
de $1.268,036 \mathrm{~m}^{2}$ e população de 7.725 habitantes, que residem em 2.128 domicílios (IBGE, 2010).

Nesse sentido, a realização de uma avaliação da qualidade ambiental urbana contribui para a compreensão das condições ambientais do meio, por intermédio da utilização de indicadores (avaliação objetiva) e com o envolvimento da população como sujeito e não objeto do processo de avaliação (avaliação subjetiva), contudo pode-se realizar também pesquisas de opinião de base amostral (BORJA, 1998). 
Desse modo, o crescimento demográfico, decorrente do processo de urbanização, pode ter comprometido a qualidade ambiental urbana de Altamira (PA), isso justifica essa pesquisa, e incrementa e relevância da mesma, pois, ela irá gerar dados à Prefeitura Municipal de Altamira quanto aos problemas ocorrentes no bairro Jardim Independente I, sob a percepção ambiental da comunidade que lá reside, e permitirá alcançar o objetivo almejado que é identificar o perfil individual dela, empregar cinco indicadores para avaliar a Qualidade Ambiental Urbana (QAU), naquele bairro e, finalmente calcular e qualificar o IQAU do bairro objeto dessa pesquisa.

\section{MATERIAL E MÉTODOS}

O estudo foi aplicado no município de Altamira, localizado na mesorregião sudoeste do estado do Pará, cujas coordenadas geográficas da sede municipal são 03012'00"S e $52^{\circ} 13^{\prime} 45^{\prime \prime}$ W, possui uma área $159.533,328$ km², sendo considerado um dos maiores municípios do mundo em extensão territorial (Figura 1)

Figura 1. Mapa de localização do município e da área de estudo. Altamira - PA.

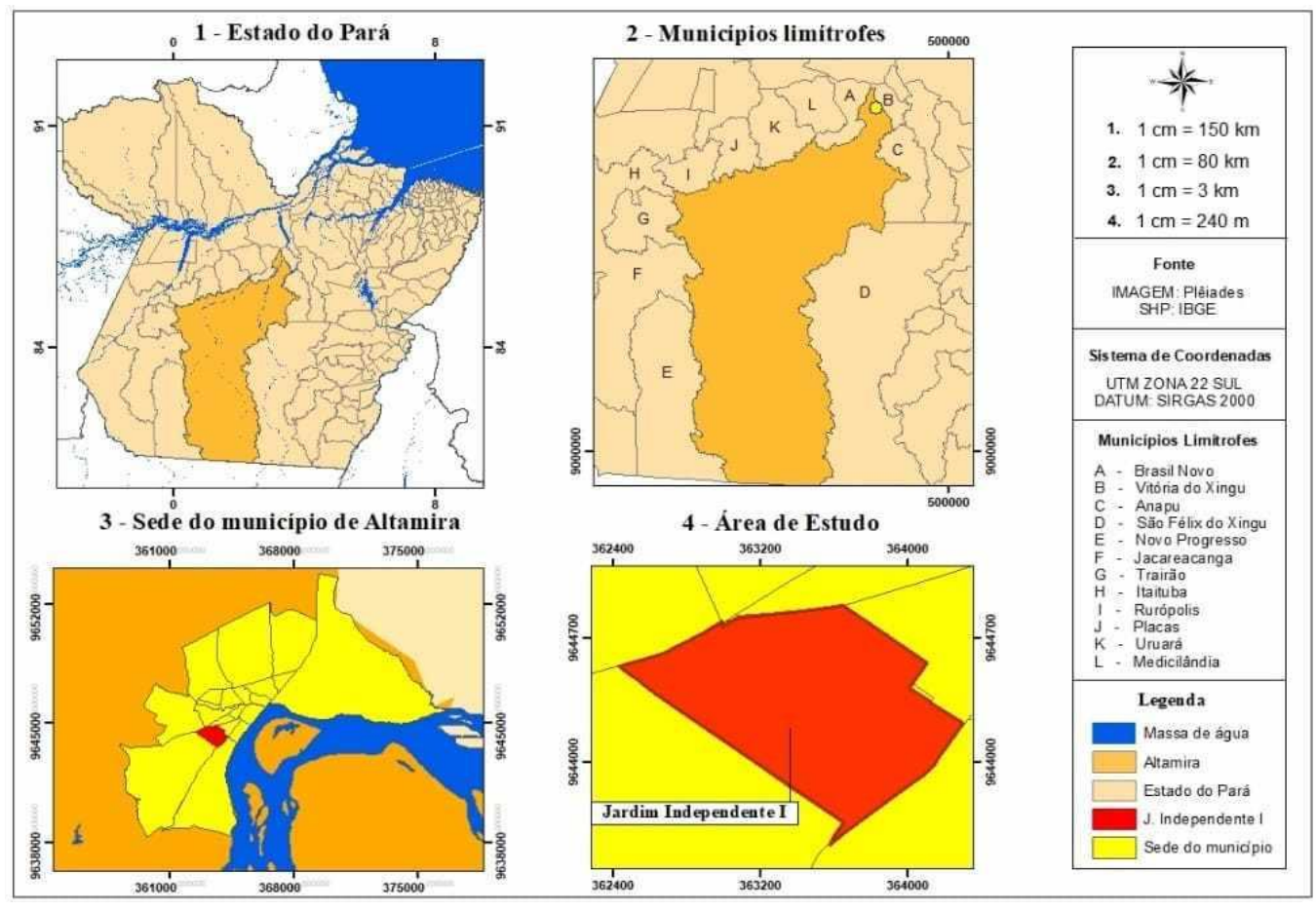

Fonte: autores (2016).

RC: 39600

Disponível em: https://www.nucleodoconhecimento.com.br/engenharia-ambiental/qualidadeambiental 
Segundo a classificação de Köppen, o município apresenta clima equatorial Am e Aw, a vegetação predominante é do tipo Floresta Aberta latifoliada (cipoal) e a Floresta Aberta Mista (cocal) e a hidrologia é composta pelo rio Xingu, tendo como principal afluente o rio Iriri (IBGE, 2016b; IDESP, 2014).

O bairro objeto dessa pesquisa foi Jardim Independente I, localizado na localizado na zona sudoeste do município de Altamira (PA). Justifica-se a escolha deste bairro, em virtude de sua existência não ser tão recente no contexto municipal, iniciado em 1987, e mesmo assim apresenta uma carência de infraestrutura. De acordo com o zoneamento estabelecido pelo Plano Diretor municipal de 2011, o bairro classifica-se predominantemente como Zona Habitacional 2, pois:

É a área habitacional onde se pretende incentivar a categoria de uso do solo residencial da subcategoria Unidade Habitacional $(\mathrm{UH})$, sob a forma de condomínios, chácaras de recreio, habitação unifamiliar em lote e habitações de interesse social, onde é permitido a categoria de uso do solo de Comércio e Prestação Serviços (CS) da subcategoria 1 (ALTAMIRA, 2011, p. 215).

Quanto a metodologia, foi empregada a pesquisa-ação exploratória, pois, de acordo com a síntese escrita por Ferreira (2011), o pesquisador realiza uma intervenção direta sobre os sujeitos da pesquisa. Para melhor aplicação da mesma, ela foi dividida em sete etapas distintas (Figura 2). 
Figura 2. Etapas e ações do método empregado para a avaliação da qualidade ambiental urbana. Bairro Jardim Independente I. Altamira - PA.

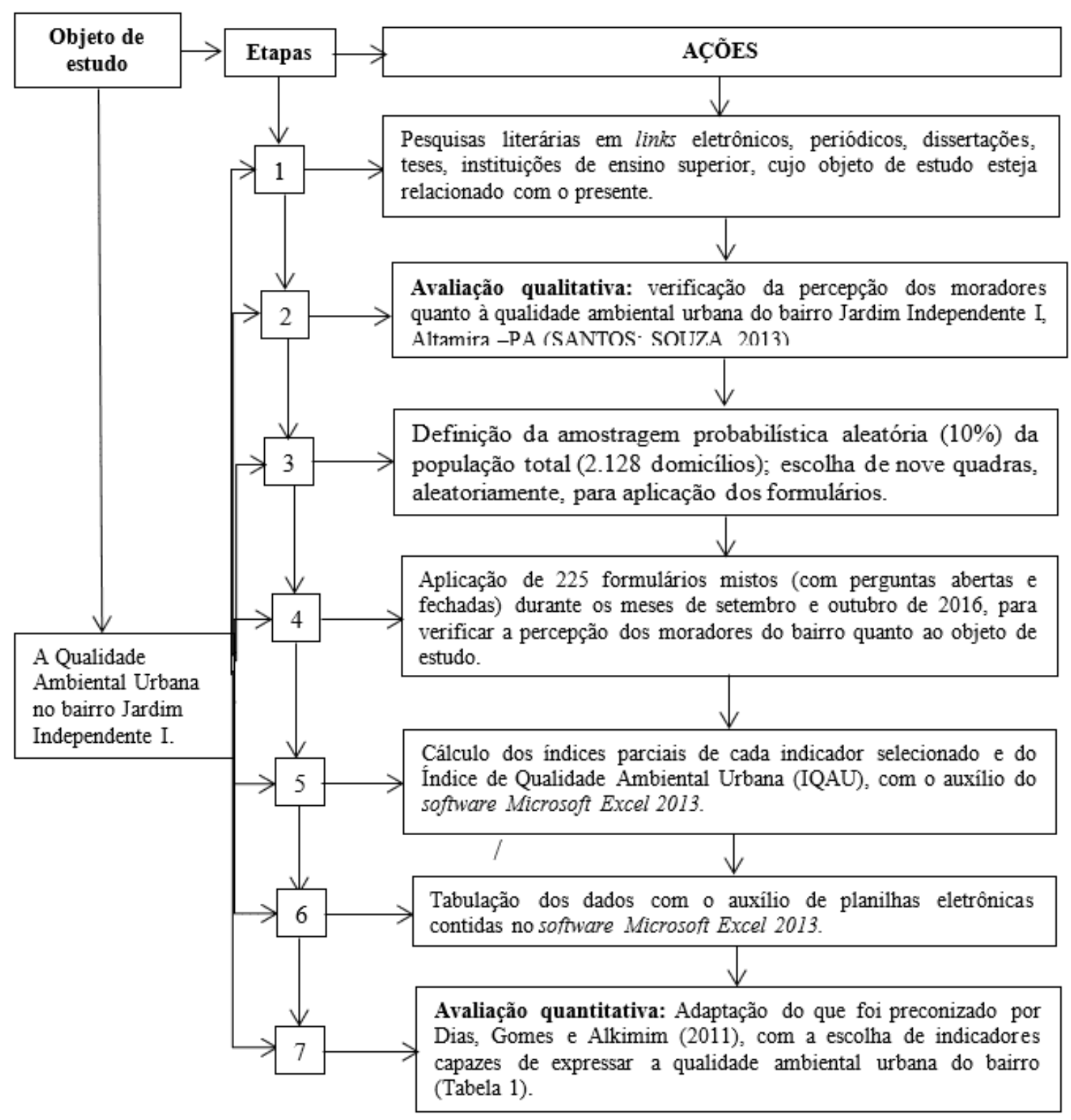

Fonte: autores (2016).

Disponível em: https://www.nucleodoconhecimento.com.br/engenharia-ambiental/qualidadeambiental 
Tabela 1. Indicadores propostos e pesos atribuídos utilizados para avaliação da qualidade ambiental urbana. Bairro Jardim Independente I, Altamira - PA.

\begin{tabular}{|c|c|c|c|c|}
\hline INDICADORES & $\begin{array}{l}\text { COMPOSIÇÃO DOS } \\
\text { INDICADORES }\end{array}$ & $\begin{array}{l}\text { ÍNDICES } \\
\text { PARCIAIS }\end{array}$ & $\begin{array}{c}\text { PESO DOS } \\
\text { INDICADORES }\end{array}$ & IQAU \\
\hline $\begin{array}{l}\text { (1) Abastecimento } \\
\text { de água }\end{array}$ & $\begin{array}{l}\text { Percentual de cobertura da rede } \\
\text { de abastecimento/100 - Iabs }\end{array}$ & $0-1$ & 30 & \\
\hline $\begin{array}{l}\text { (2) Esgotamento } \\
\text { sanitário }\end{array}$ & $\begin{array}{l}\text { Quantificação e classificação do } \\
\text { modo de disposição ou } \\
\text { afastamento dos esgotos - Ies }\end{array}$ & $0-1$ & 30 & $\stackrel{8}{\circ}$ \\
\hline $\begin{array}{l}\text { (3) Limpeza } \\
\text { pública urbana }\end{array}$ & $\begin{array}{l}\text { Percentual de cobertura dos } \\
\text { serviços de coleta de } \\
\text { resíduos } / 100 \text { - Ilpu }\end{array}$ & $0-1$ & 20 & $\begin{array}{l}+ \\
+ \\
+ \\
+ \\
+ \\
+ \\
+\end{array}$ \\
\hline $\begin{array}{l}\text { (4) Pavimentação } \\
\text { das vias }\end{array}$ & $\begin{array}{l}\text { Percentual de pavimentação das } \\
\text { vias } / 100 \text { - Ipav }\end{array}$ & $0-1$ & 10 & $\underset{\omega}{己}$ \\
\hline $\begin{array}{c}\text { (5) Cobertura } \\
\text { vegetal }\end{array}$ & $\begin{array}{l}\text { Percentual de cobertura } \\
\text { vegetal } / 100-\text { Icv }\end{array}$ & $0-1$ & 10 & \\
\hline
\end{tabular}

Fonte: adaptado de Dias, Gomes e Alkimim (2011).

Legendas: labs = Índice de abastecimento de água; les = Índice de esgotamento sanitário; IIpu = Índice de limpeza pública urbana; Ipav = Índice de pavimentação das vias; Icv: Índice de cobertura vegetal; IQAU= Índice de Qualidade Ambiental Urbana

Após a escolha desses indicadores, efetuou-se a composição. Ela mostra como os dados foram trabalhados para a obtenção dos índices parciais. Os índices parciais expressam o estado do indicador avaliado, variando de zero a um. Um indicador o qual o índice parcial obtido é zero corresponde a pior avaliação, enquanto o índice um refere-se a melhor avaliação.

A atribuição de peso aos indicadores foi realizada de acordo com o preconizado por Dias, Gomes e Alkimim (2011) e, levou-se em consideração a importância e contribuição de cada indicador para promover a qualidade ambiental urbana. Em vista disso, foram atribuídos os maiores pesos aos indicadores abastecimento de água e esgotamento sanitário devido à importância que possuem para a promoção da saúde humana e sanidade do meio ambiente. Foram necessárias seis equações para apuração dos valores componentes do IQAU (Tabela 2)

Disponível em: https://www.nucleodoconhecimento.com.br/engenharia-ambiental/qualidade- 
Tabela 2 - As seis equações utilizadas para obtenção dos valares para o IQAU.

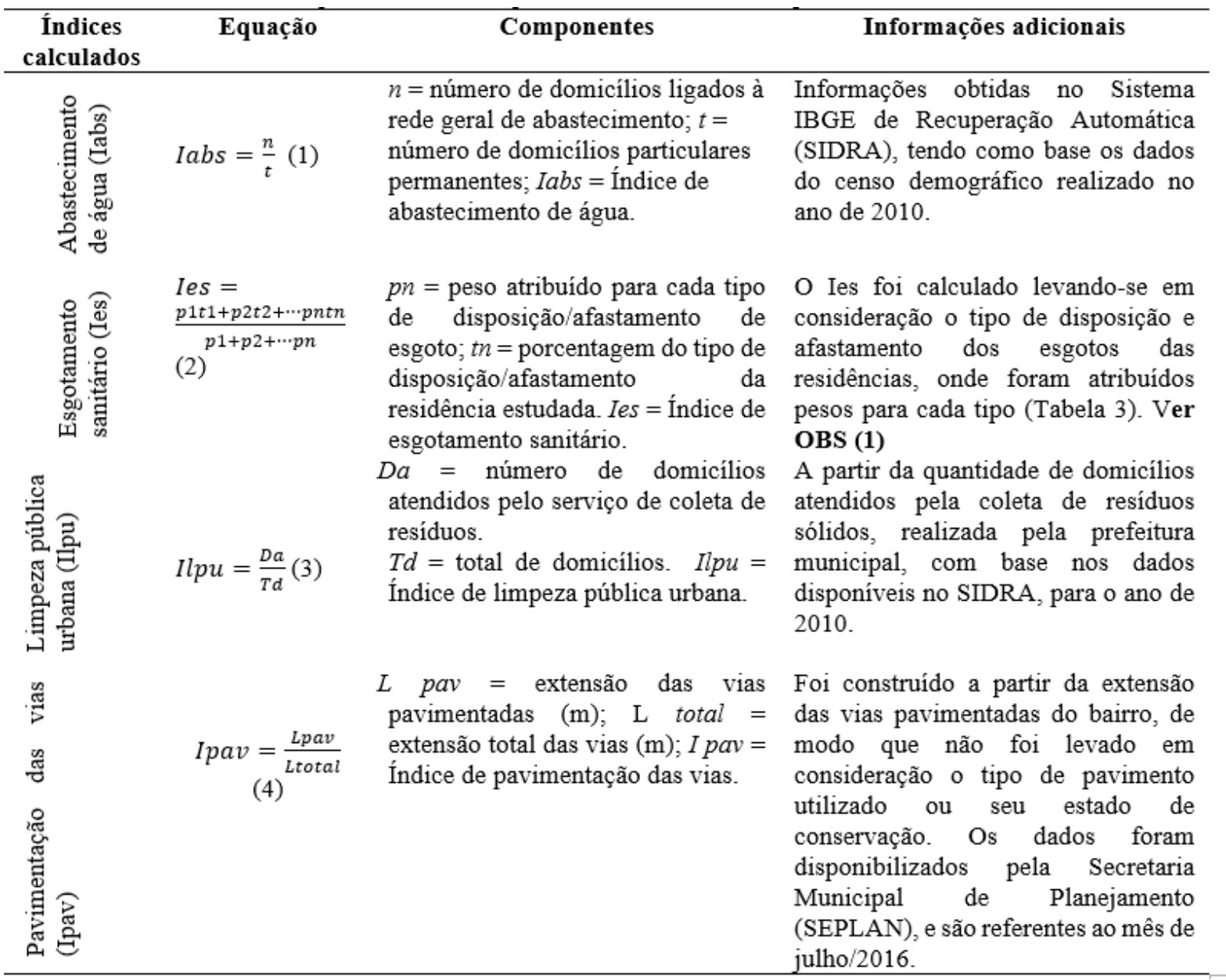

\begin{tabular}{|c|c|c|c|}
\hline $\begin{array}{c}\text { Índices } \\
\text { calculados }\end{array}$ & Equações & Componentes & Informações adicionais \\
\hline 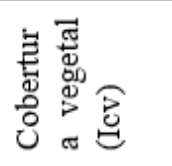 & $I c v=\frac{\text { Aveg }}{\text { Atotal }}$ & $\begin{array}{l}\text { Aveg = área de vegetação } \\
\text { (há); Atotal = área total do } \\
\text { bairro (há); Icv = Índice de } \\
\text { cobertura vegetal. }\end{array}$ & $\begin{array}{l}\text { Foi necessária a obtenção de dados referentes } \\
\text { a delimitação do bairro junto a SEPLAN } \\
\text { (VER OBS 2). }\end{array}$ \\
\hline 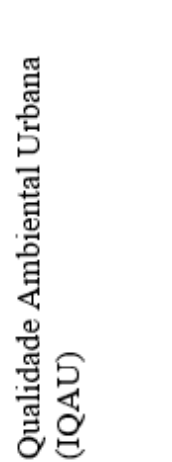 & $\begin{array}{l}I Q A U= \\
I a b s P+I e s P+ \\
I l p u P+ \\
I p a v P+I c v P \\
\quad(6)\end{array}$ & $\begin{array}{l}\text { Iabs = índice de } \\
\text { abastecimento de água; } \\
\text { Ies = índice de } \\
\text { esgotamento sanitário; } \\
\text { Ilpu = índice de limpeza } \\
\text { pública urbana; } \\
\text { Ipav = índice de } \\
\text { pavimentação das vias; } \\
\text { Icv = índice de cobertura } \\
\text { vegetal; } \\
P=\text { peso do indicador. }\end{array}$ & $\begin{array}{l}\text { Após o cálculo dos índices parciais, estes } \\
\text { foram multiplicados pelos respectivos pesos } \\
\text { dos indicadores e somados, formando o } \\
\text { IQAU. } \\
\text { Efetuou-se a classificação do IQAU de } \\
\text { acordo com os níveis apresentados, divididos } \\
\text { em cinco classes de qualidade: péssimo ao } \\
\text { ótimo (Tabela 4) }\end{array}$ \\
\hline
\end{tabular}

Fonte: autores (2016)

RC: 39600

Disponível em: https://www.nucleodoconhecimento.com.br/engenharia-ambiental/qualidadeambiental 
Tabela 3. Pesos atribuídos para cada tipo de disposição/afastamento dos esgotos.

\begin{tabular}{|l|l|}
\hline TIPO DE DISPOSIÇÃO/AFASTAMENTO DOS ESGOTOS & PESO \\
\hline Rede geral de esgoto ou pluvial & 1,0 \\
\hline Fossa séptica & 0,5 \\
\hline Fossa rudimentar & 0,3 \\
\hline Vala ou outro escoadouro & 0,2 \\
\hline Rio, lago ou mar & 0,1 \\
\hline Sem dispositivo de afastamento & 0,0 \\
\hline
\end{tabular}

Fonte: Dias, Gomes e Alkmim (2011).

Tabela 4 Valores e níveis de Qualidade Ambiental Urbana.

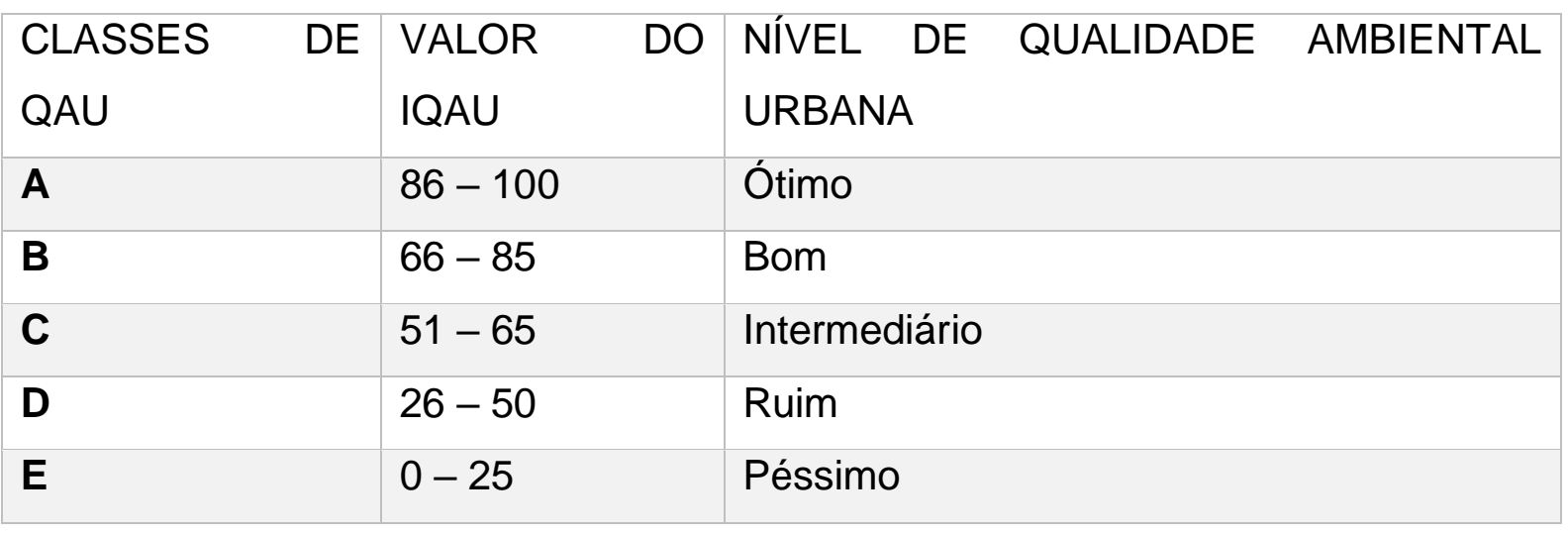

Adaptada a partir de dados contidos em Dias, Gomes e Alkmim (2011)

(OBS $\left.{ }_{1}\right)$ Para a situação ideal, o domicílio deve estar ligado à rede de esgotamento sanitário (peso 1) e como pior situação, a inexistência de tipo de disposição ou afastamento dos dejetos (peso 0). Assim, o les foi obtido por meio da somatória das médias ponderadas entre o percentual de cada forma de disposição e o seu respectivo peso atribuído. Os dados também foram obtidos no SIDRA, referente ao ano de 2010.

$\left(\mathrm{OBS}_{2}\right.$ ) Os dados foram obtidos em formato $\mathrm{km} / \mathrm{e}$ importados para o software Google Earth Pro (2017, resolução 300 pixeis) por meio da técnica de interpretação visual de imagens, foi possível identificar a cobertura vegetal[ ${ }^{[4]}$ do bairro estudado. Com o 
auxílio da ferramenta "régua/adicionar polígono" foram mensuradas as áreas cobertas por vegetação, em hectares (ha).Para interpretação do Icv, utilizou-se o preconizado por Oke (1973) que recomenda que o índice de cobertura vegetal esteja na faixa de $30 \%$, para proporcionar um adequado balanço térmico em áreas urbanas, sendo que áreas com índice inferior a 5\%, se assemelham a características de um deserto. Já a atribuição de pesos para o Icv (Tabela 5) foi realizada conforme o indicado por Dias, Gomes e Alkimim (2011).

Tabela 5 - Valores atribuídos ao Icv.

\begin{tabular}{|l|l|}
\hline ÁREA VERDE (\%) & PESOS \\
\hline $\mathbf{> 3 0}$ & 1 \\
\hline $\mathbf{5 - 3 0}$ & Método de interpolação linear \\
\hline $\mathbf{<} 5$ & 0 \\
\hline
\end{tabular}

Adaptada a partir de dados contidos em Dias, Gomes e Alkmin (2011).

\section{RESULTADOS E DISCUSSÃO}

\subsection{PERFIL INDIVIDUAL E GERAL DOS INDIVÍDUOS AMOSTRADOS}

Para o perfil individual, quanto ao gênero e grau de escolaridade, os dados obtidos e analisados indicaram houve uma superioridade do sexo feminino $(65,8 \%)$; o grau de instrução, maior frequência $(41,8 \%)$ para o ensino fundamental (Figura 3$)$. 
Figura 3. Dados sobre gênero, e grau de instrução dos indivíduos amostrados. Bairro Jardim Independente I. Altamira - PA.

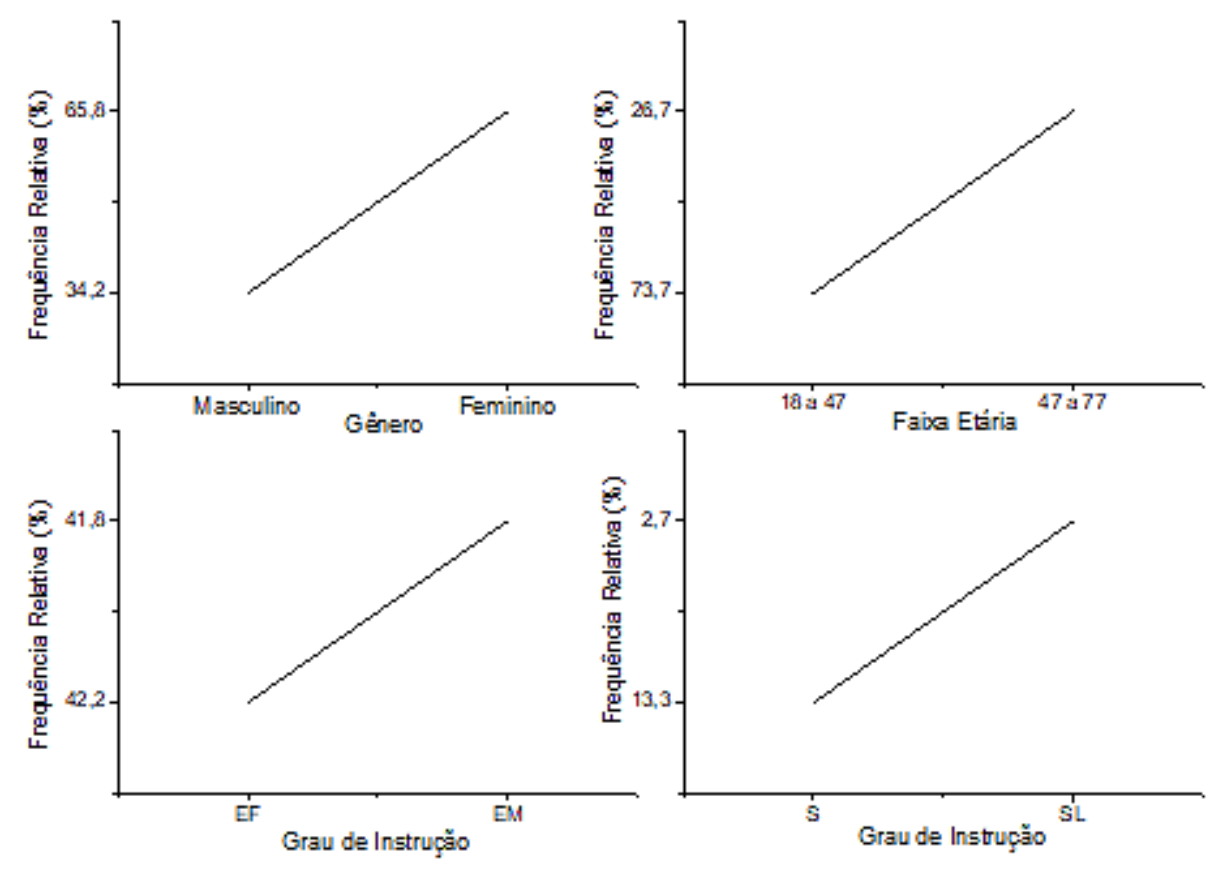

Fonte: autores (2016).

Em relação ao tempo de residência, a análise dos resultados indicou que $94,7 \%$ dos indivíduos amostrados residem de 1 a 20 anos no bairro objeto dessa pesquisa, 3,5\% mais de 20 anos e $1,8 \%$ menos de 1 ano.

No estudo realizado na Vila Parque Santa Anita, Porto Alegre (RS), por Lermen (2008), a autora concluiu que o nível de escolaridade é um fator decisivo para um maior senso crítico dos habitantes, mas que isso não resulta, obrigatoriamente, em uma maior consciência ambiental, pois a percepção dos residentes em relação ao meio em que vivem está fundamentada também em seus conhecimentos pessoais e experiências. Essa perspectiva foi encontrada no bairro analisado em Altamira. 


\subsection{PERCEPÇÃO AMBIENTAL DA COMUNIDADE E OS PROBLEMAS AMBIENTAIS}

\subsubsection{PROBLEMAS AMBIENTAIS DO BAIRRO JARDIM INDEPENDENTE I, ALTAMIRA - PA}

Os dados obtidos indicaram que, na percepção ambiental dos indivíduos amostrados, são quatro problemas ambientais (ausência de pavimentação, saneamento básico, falta de árvores e queimadas) que causam transtornos ao cotidiano dos mesmos e diminui a qualidade de vida urbana.

Sobre esse tipo de percepção, foi realizada uma pesquisa no bairro Jardim das Oliveiras, localizado em Luís Eduardo Magalhães (BA), por Santos e Souza (2013), e os dados analisados por eles, indicaram que os indivíduos amostrados identificaram como problemas ambientais, a deficiência no saneamento básico (Ex.: falta de água tratada e presença de lixo em terrenos devolutos), ausência de pavimentação nas ruas, que gera muita poeira, a queima de resíduos domésticos e de folhagens das árvores e a ausência de arborização. Essa conclusão é similar à do bairro Jardim Independente I, Altamira (PA).

\subsubsection{FALTA DE PAVIMENTAÇÃO DAS VIAS}

Para esse problema ambiental, a análise dos dados obtidos indicou uma frequência relativa com valor igual a $50,2 \%$. Foi verificado que, isoladamente, este problema alcançou um percentual igual a $6,7 \%$. Houve também a indicação de que, quando associado a outros problemas ambientais (Ex.: falta de esgoto), a porcentagem elevou-se para $20 \%$. Outra indicação de percepção associada à falta de pavimentação com outros seis problemas ambientais diferentes (falta de árvores, presença de queimadas, lixo em terrenos baldios e nas ruas, falta de água tratada, drenagem e posto de saúde), o valor decresce para 8,9\% (Figura 3). 
Figura 3. A falta de pavimentação como problema ambiental, isolada e associada. Percepção da comunidade do bairro Jardim Independente I, Altamira - PA.

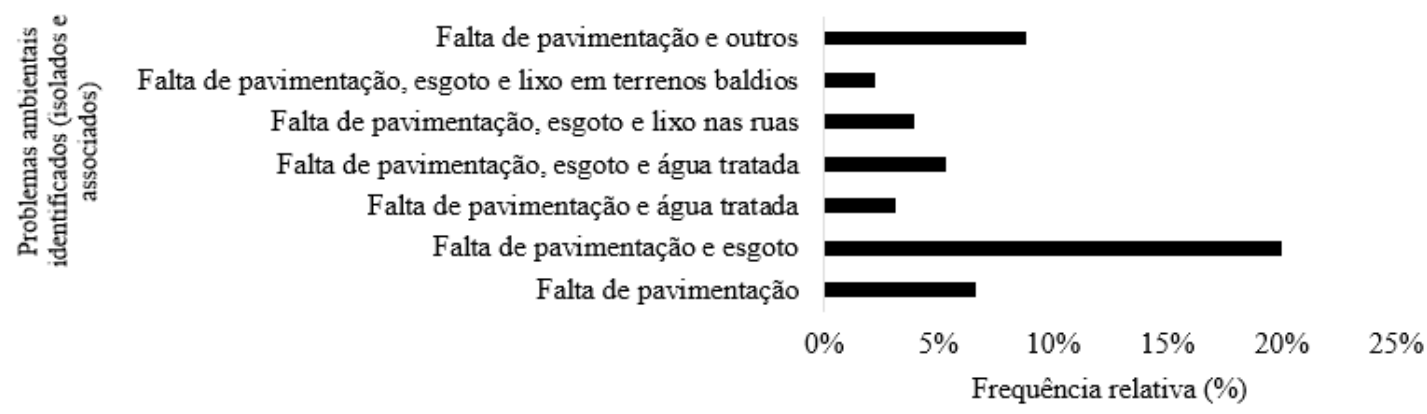

Fonte: autores (2016).

Acerca da falta de pavimentação em conjuntos habitacionais, foi efetuado um estudo em um bairro de classe baixa, em Nairóbi (Quênia), por Ngo, Kokoyo e Klopp (2017). Nele os autores concluiram que os indivíduos amostrados identificaram a falta de pavimentação nas ruas como um problema ambiental, e associaram a emissão de poeira a uma forma de poluição do ar, o que afeta a sua qualidade de vida. Isso corrobora com os dados obtidos no bairro Jardim Independente I, Altamira (PA).

\subsubsection{AUSÊNCIA DE SANEAMENTO BÁSICO (ABASTECIMENTO DE ÁGUA, ESGOTAMENTO SANITÁRIO E RESÍDUOS SÓLIDOS)}

Em relação a este problema ambiental, a análise dos dados obtidos indicou que a percepção ambiental da comunidade identificou a falta de esgoto ( $f r=17,3 \%$ ), isoladamente, como o problema ambiental que mais altera a qualidade ambiental urbana. Vale ressaltar que, a somatória das frequências relativas obtidas para o saneamento básico, alcançou 38,7\% (Figura 4).

Disponível em: https://www.nucleodoconhecimento.com.br/engenharia-ambiental/qualidade- 
Figura 4. A ausência de saneamento básico como problema ambiental, isolado e associado. Percepção da comunidade do bairro Jardim Independente I, Altamira - PA.

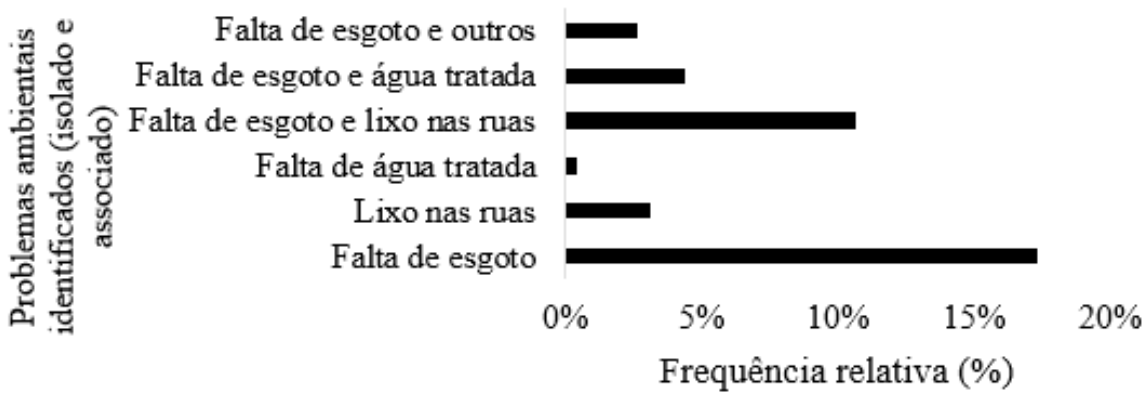

Fonte: autores (2016).

Houve também indicação de que os indivíduos amostrados associaram a falta de esgoto com outras variáveis (falta de esgoto e lixo nas ruas: $f r=10,7 \%$; falta de esgoto e água tratada: $f r=4,4 \%$ ). Todavia, um problema ambiental atual discutido com veemência pela população brasileira, lixo nas ruas, alcançou apenas a frequência relativa de $3,1 \%$. Os demais, quando associados, obtiveram uma frequência relativa compreendida entre $0,4 \%$ a $1,3 \%$.

Em relação a esses problemas ambientais, a pesquisa realizada no município de Dona Inês (PB), por Maciel, Felipe e Lima (2015), indicou que a precariedade dos serviços de saneamento básico é notória em grande parte dos municípios brasileiros, pois, a não disponibilidade de água de boa qualidade, falta de tratamento e disposição adequada dos esgotos e o inadequado destino dos resíduos, gera consequências como a proliferação de doenças e a degradação do meio ambiente. No bairro Jardim Independente I, em Altamira, foram similares àqueles obtidos em Dona Inês.

\subsubsection{QUEIMADAS}

Neste índice, os dados analisados indicaram que não houve percepção ambiental quanto a isso, por parte dos indivíduos amostrados. Mas, quando associado a problemas referentes ao saneamento básico, a frequência relativa total obteve um valor igual a 4\%. Outra associação do problema em tela, foi com a falta de esgoto e

Disponível em: https://www.nucleodoconhecimento.com.br/engenharia-ambiental/qualidadeambiental 
lixo nas ruas, que obteve a maior frequência relativa $(1,3 \%)$. No entanto, quando associada aos demais problemas (falta de esgoto, lixo nas ruas e outros) alcançou a frequência relativa de $0,9 \%$ em cada (Figura 5 ).

Figura 5. As queimadas como problema ambiental, associado. Percepção da comunidade do bairro Jardim Independente I, Altamira - PA.

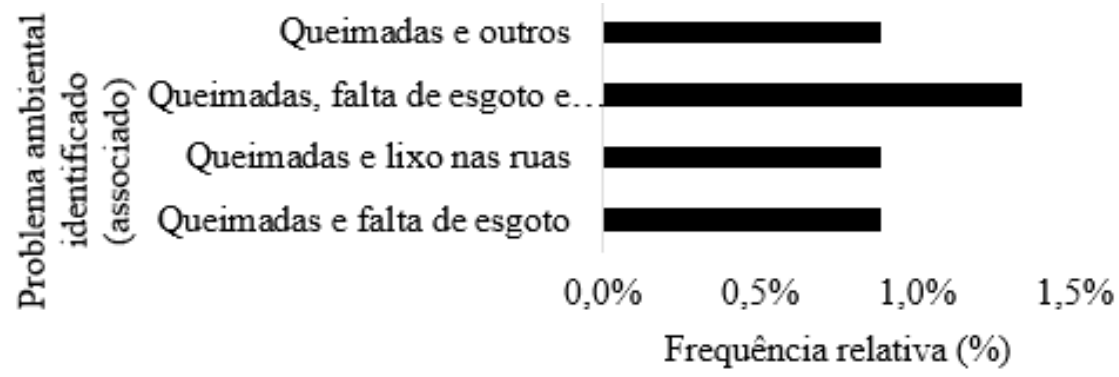

Fonte: autores (2016).

A análise dos resultados indicou também que as queimadas vêm sendo adotadas por parte da população do bairro Jardim Independente I, Altamira - PA, como uma forma de disposição final de resíduos sólidos domiciliares, o que pode causar danos ao meio ambiente e a saúde humana. Estudo efetuado em Lokoja, (Nigéria), por Adetunji, Atomode e Isah (2015), constatou que a maioria dos entrevistados tem o hábito de queimar os resíduos, e que essa forma de gestão dos resíduos sólidos é considerada insalubre, pois contribui para a poluição atmosférica local. Isso corrobora com o que indicou a pesquisa efetuada no bairro Jardim Independente I, em Altamira.

\subsubsection{AUSÊNCIA DE ARBORIZAÇÃO}

Quanto a esse problema ambiental, os resultados indicaram que houve baixa percepção desse tipo de problema de forma isolada ( $f r=0,4 \%$ ). Mas, em associação com outros problemas ambientais (Ex.: falta de esgoto), houve uma elevação dessa frequência ( $f r=1,8 \%$ ) e, com isso, verificou-se que a frequência acumulada alcançou um valor igual a $3,1 \%$ (Figura 6 ). 
Figura 6. Ausência da arborização como problema ambiental, isolado e associado. Percepção da comunidade do bairro Jardim Independente I, Altamira - PA.

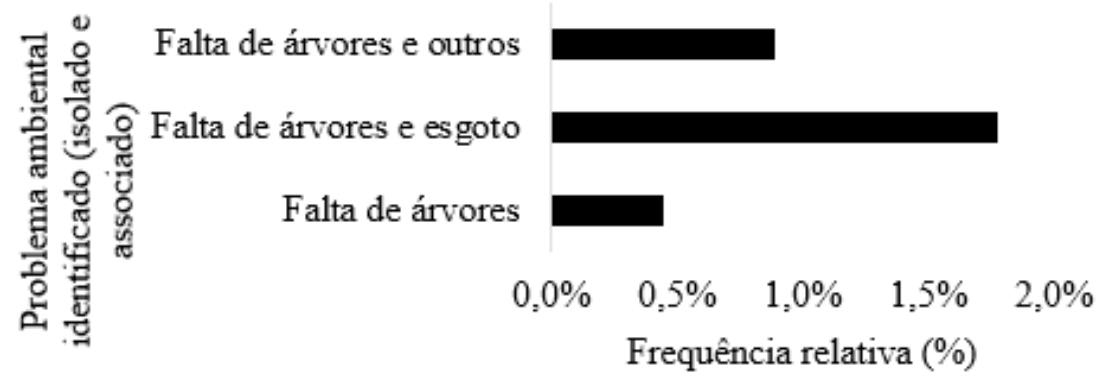

Fonte: autores (2016).

A pesquisa efetuada por Nucci (2008) no distrito de Santa Cecília, São Paulo (SP), acerca da ecologia e planejamento da paisagem, indicou que a cobertura vegetal, diferentemente da terra, do ar e da água, não é uma necessidade óbvia na cena urbana, e que está relacionada como uma função de satisfação psicológica e cultural para os indivíduos. A análise efetuada nos dados obtidos em Altamira, indicou uma similaridade de ideias com as obtidas na cidade de São Paulo, pois a maioria dos habitantes não associa a falta de árvores a um problema ambiental do bairro Jardim Independente I.

\subsubsection{OUTROS PROBLEMAS IDENTIFICADOS}

A análise dos dados obtidos indicou que os indivíduos amostrados possuem percepção para outros tipos de problemas (Ex.: iluminação pública; ausência de Unidade Básica de Saúde; segurança pública e áreas de lazer) e que eles afetam a qualidade de vida, embora a o valor da frequência relativa seja igual a $4 \%$. Quanto à segurança pública e saúde pública, em Cúcuta (Colômbia), Ortega, Díaz e Lozano (2016), realizaram pesquisa e os indivíduos amostrados associaram a ineficiência da segurança pública, a ausência de serviços de saúde (posto de saúde) e a escassez de áreas de lazer a problemas ambientais que afetam a qualidade de vida no bairro, o que também ocorreu na pesquisa realizada no bairro Jardim Independente I. 


\subsubsection{PROBLEMAS QUE MAIS INTERFEREM NA QUALIDADE AMBIENTAL DO BAIRRO}

Para esse tema, os dados obtidos indicaram a identificação, pelos indivíduos amostrados, de sete problemas ambientais: (1) esgoto a céu aberto, (2) falta de água tratada, (3) falta de pavimentação, (4) lixo nas ruas e em terrenos baldios, (5) coleta de lixo malfeita, (6) queimadas e (7) falta de árvores (Figura 7).

Figura 7. Problema que mais interfere na qualidade ambiental. Percepção da comunidade do bairro Jardim Independente I, Altamira - PA.

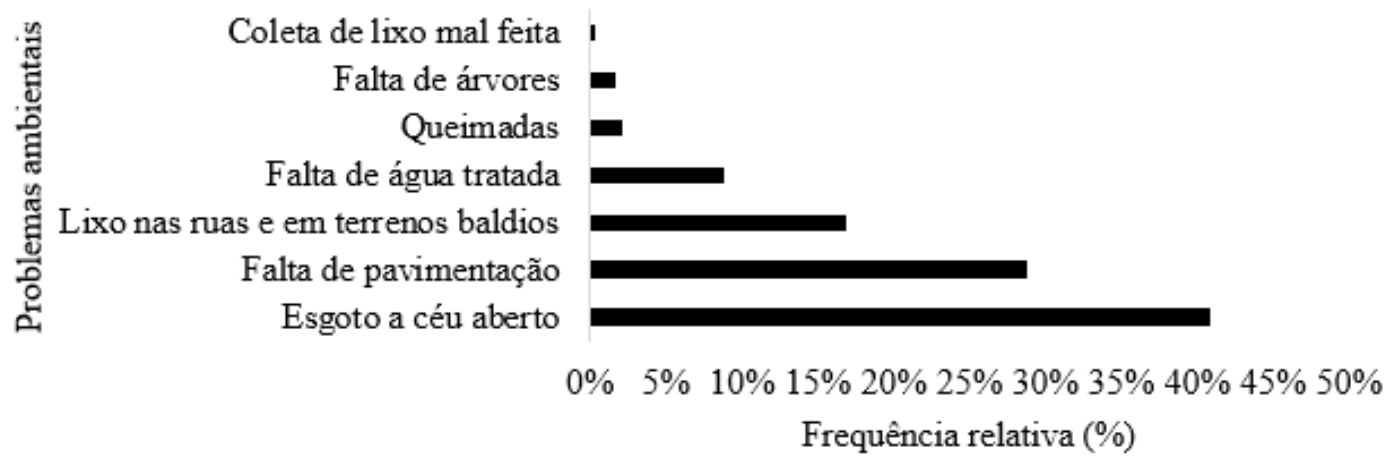

Fonte: autores (2016).

Dos sete problemas identificados, os maiores valores encontrados foram esgoto a céu aberto $(40,9 \%)$ e falta de pavimentação nas vias públicas $(28,9 \%)$. Os indivíduos amostrados indicaram que esses dois problemas ambientais, afetam diretamente a qualidade de vida deles, pois, em períodos chuvosos, ambos os problemas (Figura 8) eles apresentam tendência a se agravar. 
Figura 8. Esgoto lançado diretamente nas vias públicas do bairro Jardim Independente I, Altamira - PA.

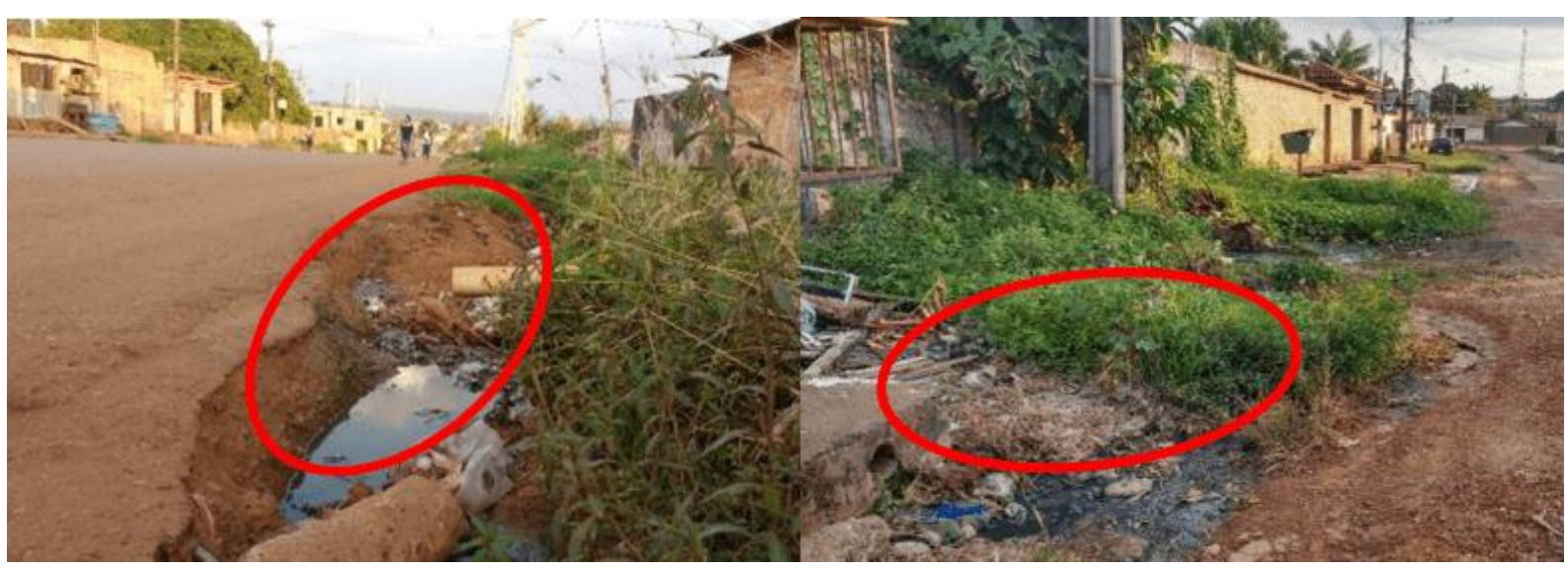

Fonte: autores (2016).

Acerca desses dois problemas ambientais, foi efetuado um estudo no bairro Santa Cruz, município de Luís Eduardo Magalhães (BA), por Santos e Souza (2014). Nele, os autores concluíram que os indivíduos amostrados identificaram o esgoto a céu aberto como o problema ambiental que mais the causa transtornos. Esse fato indica o quanto a população também se sente incomodada com a ausência do sistema esgotamento sanitário, por associar o esgoto a céu aberto com problemas na saúde pública. Assim, a falta desse sistema indicaria que o ambiente não é "saudável", além do mau cheiro, que pode ser percebido facilmente pelos habitantes. A análise dos resultados obtidos em Altamira, corroboram com aqueles descritos por Santos e Souza (2014).

\subsubsection{SOLUÇÕES PARA OS PROBLEMAS AMBIENTAIS DO BAIRRO}

A análise dos resultados quanto a percepção dos indivíduos amostrados sobre estas soluções, indicou que a implantação dos serviços de saneamento básico ( $f r=28 \%)$ e a pavimentação das vias ( $f r=24 \%$ ), são as principais soluções para os problemas ambientais identificados (Figura 9).

Disponível em: https://www.nucleodoconhecimento.com.br/engenharia-ambiental/qualidadeambiental 
Figura 9. Soluções apontadas para os problemas ambientais. Percepção da comunidade do bairro Jardim Independente I, Altamira - PA.

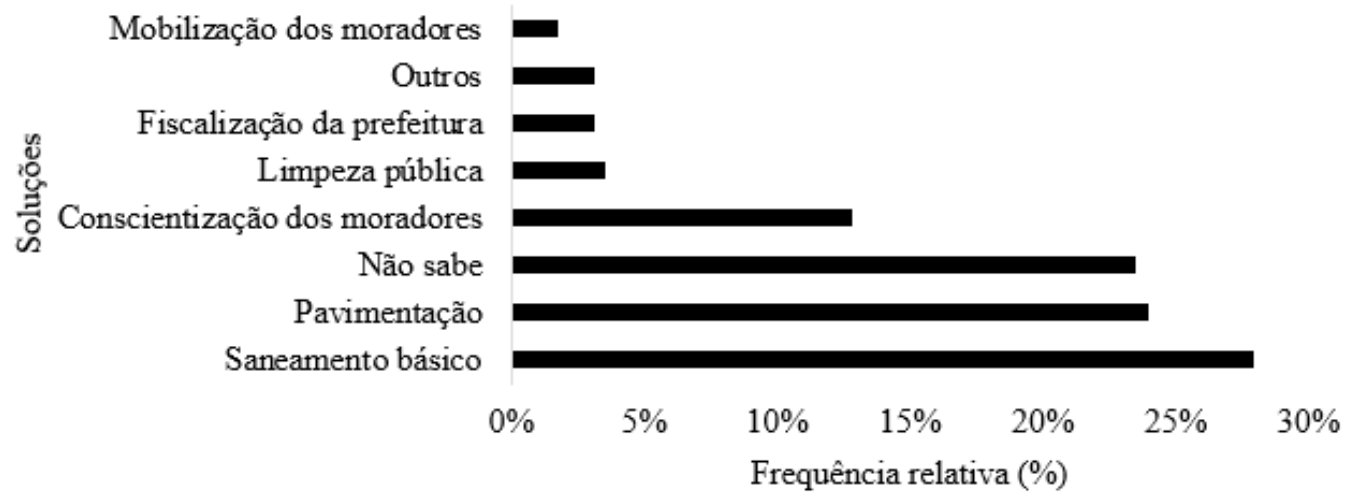

Fonte: autores (2016).

Pesquisa realizada em Salvador (BA), por Rego et al. (2013), indicou que os serviços de saneamento básico possuem importância vital para a promoção da saúde da sociedade e do meio ambiente, pois a deficiência de acesso a esses serviços pela população, com frequência, resulta em sérias implicações para as condições de saúde dos indivíduos, elevando os indicadores de incidência e prevalência de doenças. Isso corrobora com o que foi obtido na pesquisa realizada em Altamira.

\subsubsection{RESPONSABILIDADE SOBRE OS PROBLEMAS AMBIENTAIS DO BAIRRO}

A análise dos dados obtidos indicou que os indivíduos amostrados atribuíram a responsabilidade sobre os problemas ambientais ( $f r=60 \%$ ). à Prefeitura Municipal de Altamira (PMA). Foi indicado também que os moradores também são responsáveis (20\%), por alguns deles como, por exemplo, disposição final dos resíduos sólidos em locais inadequados (Figura 10). 
Figura 10. Responsáveis pelos problemas ambientais. Percepção da comunidade do bairro Jardim Independente I, Altamira - PA.

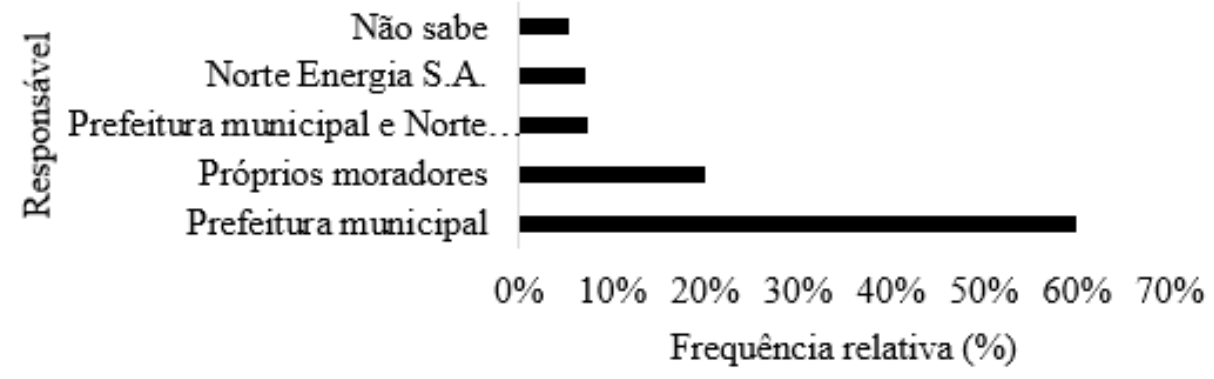

Fonte: autores (2016).

Houve também, nos resultados obtidos, a partir da percepção dos indivíduos amostrados, a indicação da empresa Norte Energia S.A. como responsável pelos problemas ambientais ocorrentes no bairro, por não estar em funcionamento, ainda, o sistema de abastecimento de água e esgotamento sanitário no município.

Pesquisa realizada em Vitória (ES), por Fernandes et al. (2008), indicou que a responsabilidade sobre os problemas ambientais é de todos e que isso demonstra um bom nível de percepção ambiental dos indivíduos amostrados. Os resultados obtidos no bairro Jardim Independente I, Altamira, divergiram daqueles obtidos em Vitória, pois a maioria dos indivíduos amostrados atribuíram ao poder público a responsabilidade sobre os problemas ambientais.

\subsubsection{COMPARAÇÃO ENTRE O BAIRRO JARDIM INDEPENDENTE I E OS DEMAIS BAIRROS DA CIDADE, EM RELAÇÃO AO MEIO AMBIENTE}

$\mathrm{Na}$ análise dos resultados obtidos em relação ao processo comparativo do momento atual no Jardim Independente I com os demais bairros da cidade de Altamira (PA), verificou-se que os indivíduos amostrados possuem percepções positivas e negativas a respeito do bairro. As percepções negativas alcançaram a frequência relativa de $70,2 \%$ e as positivas representaram $28,4 \%$ (Figura 11 ). 
Figura 11. Comparação do bairro Jardim Independente I e os demais bairros, em relação ao meio ambiente. Percepção da comunidade do bairro Jardim Independente I, Altamira - PA.

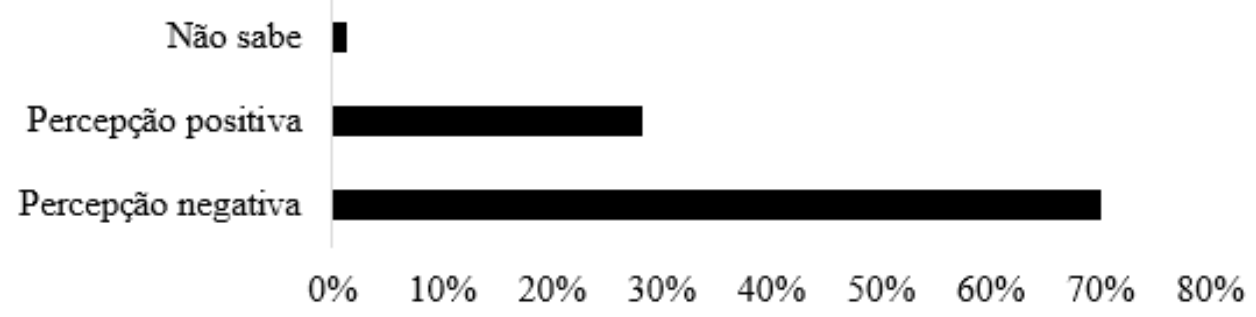

Fonte: autores (2016).

A análise desses resultados indicou três frases que exprimem bem a percepção dos indivíduos amostrados quanto aos outros bairros e o Jardim Independente I:

(1) "Apresenta os mesmos problemas que os outros bairros.". (2) "É um bairro esquecido pelos governantes.". (3) "O bairro centro é melhor." Pesquisa realizada em Medianeira (PR), por Mucelin e Bellini (2008), indicou que a população dessa localidade acredita que os bairros centrais e nobres recebem melhores cuidados pela administração pública municipal, e que as áreas periféricas são deixadas em segundo plano. Isso corrobora com os resultados encontrados no bairro Jardim Independente I, Altamira - PA.

\section{APLICAÇÃO DOS CINCO ÍNDICES DO QAU}

Os valores dos cinco índices aplicados, resultados obtidos indicaram, em uma escala decrescente, os seguintes valores para os cinco índices parciais calculados: $\| p u=$ $0,95>$ lpav $=0,69>$ lcv $=0,35>$ les $=0,17>$ labs $=0,07$ (Tabela 5). 
Tabela 5. Valores obtidos para os cinco índices analisados, bairro Jardim Independente I. Altamira - PA.

\begin{tabular}{|c|c|c|c|c|c|c|c|c|c|c|}
\hline $\begin{array}{l}\text { ÍNDICE } \\
S\end{array}$ & DA & DT & $\operatorname{EVP}(\mathrm{m})$ & $\operatorname{ETV}(\mathrm{m})$ & $\begin{array}{l}\text { ACV } \\
\text { (ha) }\end{array}$ & AB (ha) & $\begin{array}{l}\text { CV } \\
(\%)\end{array}$ & VIP & $\begin{array}{l}\mathrm{VI} \\
\mathrm{Px} \\
\mathrm{P}\end{array}$ & $\begin{array}{l}\text { V } \\
\text { F }\end{array}$ \\
\hline labs & 154 & $\begin{array}{l}2.12 \\
8\end{array}$ & -- & -- & -- & -- & -- & $\begin{array}{l}0,0 \\
7\end{array}$ & 30 & $\begin{array}{l}2 \\
1\end{array}$ \\
\hline les & -- & -- & -- & -- & -- & -- & -- & $\begin{array}{l}0,1 \\
7\end{array}$ & 30 & $\begin{array}{l}5 \\
1\end{array}$ \\
\hline IIpu & $\begin{array}{l}2.01 \\
0\end{array}$ & $\begin{array}{l}2.12 \\
8\end{array}$ & -- & -- & -- & -- & -- & $\begin{array}{l}0,9 \\
5\end{array}$ & 20 & 19 \\
\hline Ipav & -- & -- & $\begin{array}{l}17.276,3 \\
9\end{array}$ & $\begin{array}{l}25.087,5 \\
3\end{array}$ & -- & -- & -- & $\begin{array}{l}0,6 \\
9\end{array}$ & 10 & $\begin{array}{l}6 \\
9\end{array}$ \\
\hline Icv & -- & -- & -- & -- & $\begin{array}{l}17,3 \\
8\end{array}$ & $\begin{array}{l}126,803 \\
6\end{array}$ & $\begin{array}{l}13 \\
7\end{array}$ & $\begin{array}{l}0,3 \\
5\end{array}$ & 10 & $\begin{array}{l}3 \\
5\end{array}$ \\
\hline
\end{tabular}

Fonte: autores (2016).

Legendas: labs= Índice de abastecimento de água, les= Índice de esgotamento sanitário, Ilpu = Índice de limpeza pública urbana, Ipav= Índice de pavimentação, Icv = Índice de cobertura vegetal, $\mathrm{DA}=$ Domicílios Atendidos, $\mathrm{DT}=$ Domicílios Totais, $E V P=$ Extensão das Vias Pavimentadas, ETV= Extensão Total das Vias, ACV= Área de Cobertura Vegetal, $\mathrm{AB}=$ Área do Bairro, $\mathrm{CV}=$ Cobertura Vegetal, $\mathrm{VIP}=$ Valor do Índice Parcial, $\mathrm{P}=\mathrm{Peso}, \mathrm{VF}=$ Valor Final.

\section{1 ÍNDICE DE ABASTECIMENTO DE ÁGUA (IABS)}

A análise do resultado obtido indicou, para o labs, um valor igual a 0,07. Em função desse valor, pôde-se concluir que o abastecimento está inadequado, pois, quanto mais distante de 1, pior é a qualidade ambiental urbana, e esse também foi o menor índice obtido, dentre os que foram analisados no bairro. Quanto à infraestrutura 
referente ao abastecimento, a estação de tratamento de água e a rede de distribuição foram reformadas e ampliadas, como uma das condicionantes da Usina Hidrelétrica de Belo Monte (UHEBM), e ainda não estão em funcionamento no bairro.

Pesquisa realizada em 15 municípios da Zona da Mata (MG), por Lisboa, Heller e Silveira (2013), indicou que o abastecimento de água, sendo um componente dos serviços de saneamento básico, é essencial para a promoção da saúde pública, pois a água disponível em quantidade e qualidade adequadas representa uma condição de prevenção de doenças, em contrapartida, água em quantidade insuficiente ou de qualidade insatisfatória para o consumo humano, poderá ser causadora de doenças. Isso corrobora com os resultados obtidos no bairro Jardim Independente I, Altamira (PA).

\section{2 ÍNDICE DE ESGOTAMENTO SANITÁRIO (IES)}

A análise dos dados obtidos, para o les, indicou um valor bem abaixo de $1(0,17)$. No bairro objeto dessa análise, a principal forma de disposição do esgoto é a fossa rudimentar, também conhecida como fossa negra. Historicamente, foi verificado que o sistema de esgotamento sanitário foi instalado no município no final de 2014, porém ainda não está em funcionamento.

Estudo realizado nas 100 maiores cidades do país, pelo Instituto Trata Brasil (2016), concluíram que no ano de 2010, sete, dos dez piores municípios em coleta de esgotos, pertenciam as regiões Norte e Nordeste, e verificou também, que na maioria das cidades, há uma relação entre a falta de esgotos e altas taxas de internação por diarreia, principalmente de crianças entre 0 e 5 anos.

\section{3 ÍNDICE DE LIMPEZA PÚBLICA URBANA (ILPU)}

A análise do resultado indicou, para o llpu, valor muito próximo de $1(0,95)$. Esse resultado indica que os serviços relacionados à coleta, transporte e disposição final dos resíduos sólidos estão satisfatórios no bairro estudado. O resultado da análise efetuada também indicou que os próprios habitantes colocam os resíduos fora do 
horário de coleta e se esta não for realizada por algum motivo, a maioria dos moradores não possuem o hábito de retornar os resíduos para suas casas. Cabe ressaltar, também, que esse foi o maior índice parcial encontrado no bairro Jardim Independente I, Altamira - PA.

Pesquisa efetuada em Pombal (PB), por Martins et al. (2014), indicou que a coleta dos resíduos sólidos deve ser realizada sempre nos mesmos dias da semana e em horários regulares, porque deste modo, a população se adaptará a colocar o lixo para fora de suas residências nos dias e horários adequados para o recolhimento. A pesquisa realizada em Altamira, indicou resultados similares ao encontrado em Pombal (PB).

\section{4 ÍNDICE DE PAVIMENTAÇÃO DAS VIAS (IPAV)}

A análise do resultado obtido, indicou um valor para o Ipav igual a 0,69. Isso denota que mais de dois terços das vias do bairro possuem algum tipo de pavimentação. A análise indicou também que algumas ruas do bairro estavam em processo de pavimentação asfáltica, o que tende a elevar esse índice, após a conclusão dessa pesquisa.

Estudo realizado em Palmas (TO), por Kran e Ferreira (2006), foi conclusivo quanto a geração de problemas ambientais, como a falta de pavimentação das vias à população. Dentre eles, a incidência de doenças respiratórias, em razão do incremento de partículas de poeira no ar atmosférico, durante o período seco, e a dificuldade do fluxo de veículos, inclusive os utilizados para a coleta de resíduos, especialmente nos períodos chuvosos, devido as condições inadequadas de trafegabilidade. Em Altamira, no bairro Jardim Independente I, a análise dos resultados foi diferente, posto que, dois terços das vias já apresentam algum tipo de pavimentação. 


\section{5 ÍNDICE DE COBERTURA VEGETAL (ICV)}

O resultado obtido para o índice em tela, indicou um valor igual a 0,35. Como a cobertura vegetal do bairro não atingiu a porcentagem de 30\%, recomendada pelo estudo pioneiro efetuado por Oke, (1973), o Icv apresentou um valor baixo, o que é um fator preocupante, devido aos problemas que a falta de cobertura vegetal causa nas cidades (Ex.: alterações no microclima) e os consequentes efeitos à saúde humana e ao meio ambiente, o que foi observado durante a pesquisa realizada no bairro, pois não foi identificado nenhuma área de recreação, como praças, parques e bosques.

Pesquisa realizada no bairro de Santa Felicidade, Curitiba (PR), por Moura e Nucci (2008), indicou que a cobertura vegetal deve ser um componente de relevância no planejamento urbano, assim como qualquer outra infraestrutura, para se garantir uma boa qualidade ambiental nas cidades, pois a remoção da cobertura vegetal, de todos os tipos, é necessária para dar lugar às estruturas urbanas, o que afeta a qualidade ambiental e de vida da população. A partir do valor obtido para o índice em discussão na área de estudo, em Altamira, há similaridade com o encontrado em Santa Felicidade.

\section{6 ÍNDICE DE QUALIDADE AMBIENTAL URBANA (IQAU)}

O valor obtido para o IQAU, foi igual a 36,6. Isso indica que o nível de qualidade ambiental urbana é ruim (Tabela 6).

Tabela 6: Índice de qualidade ambiental urbana do bairro Jardim Independente I, Altamira - PA.

\section{IQAU}

36,6 Ruim

Fonte: autores (2016). 
Estudo efetuado na bacia do Ribeirão do Lipa, Cuiabá (MT), por Dias, Gomes e Alkmim (2011) concluiu que, dos 16 bairros analisados, apenas dois apresentaram o índice ruim, e um deles é o Jardim Florianópolis, que pode ter o IQAU atribuído aos baixos índices de cobertura vegetal, pavimentação e esgotamento sanitário e que os problemas apresentados nesse bairro são característicos de ocupações que surgiram sem o planejamento e infraestrutura necessária.

A pesquisa realizada em Altamira, no bairro Jardim Independente I, indicou que o valor do IQAU está relacionado aos baixos índices de abastecimento de água $(0,07)$, esgotamento sanitário $(0,17)$ e cobertura vegetal $(0,35)$, o que reflete as principais deficiências que o bairro apresenta, isso em função das localizações geográficas e percepções ambientais diferentes dos indivíduos amostrados em ambas as pesquisas.

\section{CONCLUSÃO}

A percepção ambiental dos habitantes do bairro Jardim Independente I não foi dependente do grau de escolaridade, mas sim da visão que possuem sobre qualidade de vida e ambiental, devido a estratégia aplicada durante a coleta de dados, que envolveu elementos caracterizadores da qualidade ambiental, por exemplo, resíduos sólidos, esgoto a céu aberto, ausência de pavimentação em ruas e avenidas. Por isso, tal percepção mostrou-se eficaz na identificação dos problemas ambientais e dos responsáveis por esses, ora ocorrentes naquela localidade.

Os valores encontrados para o Índice de Qualidade Ambiental Urbana (IQAU), indicaram que a qualidade de vida e ambiental daquela comunidade, atualmente, está comprometida e bem abaixo dos índices considerados aceitáveis e mantenedores de uma qualidade que proporcione uma relação saudável, a partir de condições ambientais mínimas.

Desse modo, há a necessidade de ações envolvidas com o planejamento e gestão urbana para mitigação dos problemas existentes naquele bairro, especialmente aqueles considerados essenciais, como saneamento básico (abastecimento de água,

Disponível em: https://www.nucleodoconhecimento.com.br/engenharia-ambiental/qualidadeambiental 
coleta de resíduos sólidos, esgotamento sanitário), cobertura vegetal e pavimentação, atualmente deficientes.

\section{REFERÊNCIAS}

ADETUNJI, M. A.; ATOMODE, T. I.; ISAH, I. O. Assessment of Solid Waste Management in Lokoja, Nigeria. Jordan Journal of Earth and Environmental Sciencies. Jordan, v. 7, n. 2, p. 103-108, 2015.

ALTAMIRA. Prefeitura Municipal de Altamira-PA. Lei n. 2.178 de 07 de abril de 2011. Processo de Revisão do Plano Diretor do município de Altamira-PA. Relatório final, v. 2, 2011.

BORJA, P. C. Avaliação da qualidade ambiental urbana: uma contribuição metodológica. 1997. 239 f. Dissertação (Mestrado em arquitetura e urbanismo), Universidade Federal da Bahia, Salvador, 1997.

BORJA, P. C. Metodologia para a avaliação da qualidade ambiental urbana em nível local. In: XXVI CONGRESO INTERAMERICANO DE INGENIERÍA SANITARIA Y AMBIENTAL, 1998, Lima. Anais... Lima: AIDIS, 1998.

BRASIL. Lei n. 6.938, de 31 de agosto de 1981. Dispõe sobre a Política Nacional do Meio Ambiente, seus fins e mecanismos de formulação e aplicação, e dá outras providências. Diário Oficial da República Federativa do Brasil, Seção 1, p. 16.509, Brasília, DF, 1981.

BRASIL. Constituição (1988). Constituição da República Federativa do Brasil, de 5 de outubro de 1988. Diário Oficial da República Federativa do Brasil, Seção 1, p.1, Brasília, DF, 1988.

BRASIL. Lei n. 10.257, de 10 de julho de 2001. Regulamenta os arts. 182 e 183 da Constituição Federal, estabelece diretrizes gerais da política urbana e dá outras 
providências. Diário Oficial da República Federativa do Brasil, Seção 1, p. 1, Brasília, DF, 2001.

BRASIL. Lei n.11.445, de 5 de janeiro de 2007. Estabelece diretrizes nacionais para o saneamento básico; altera as Leis nos 6.766, de 19 de dezembro de 1979, 8.036, de 11 de maio de 1990, 8.666, de 21 de junho de 1993, 8.987, de 13 de fevereiro de 1995; revoga a Lei no 6.528, de 11 de maio de 1978; e dá outras providências. Diário Oficial da República Federativa do Brasil, Seção 1, p. 3, Brasília, DF, 2007.

BUENROSTRO, O.; MÁRQUEZ, L.; OJEDA, S. Environmental perception of solid waste management in the municipalities of Pátzcuaro Region, Mexico. Environmental Engineering and Management Journal. Romania, v. 13, n. 12, p. 3097-3103, 2014.

CELEMÍN, J. P.; VELÁZQUEZ, G. A. Elaboración y aplicación de un índice de calidad ambiental para la región del nordeste argentino, 2010. Economía, sociedad y território. México, v. 15, n. 47, p. 123-151, 2015.

CLAPP, B. W. An environmental history of Britain since the Industrial Revolution. Routledge, 2014.

DIAS, F. D. A; GOMES, L. A; ALKMIM, J. K. D. Avaliação da qualidade ambiental urbana da bacia do Ribeirão do Lipa através de indicadores, Cuiabá/MT. Sociedade e Natureza. Uberlândia, v. 23, n. 1, p. 127-147, 2011.

EEA. European Environment Agency. Digest of EEA indicators 2014. Luxembourg: Publications Office of the European Union, 2014. Disponível em: <http://www.eea.europa.eu/publications/digest-of-eea-indicators-2014>. Acesso em: 02 jun. 2016.

EEA. European Environment Agency. Environmental Terminology and Discovery Service (ETDS). 2016.2 Disponível em: <http://glossary.eea.europa.eu/terminology/concept_html?term=environmental\%20qu ality>. Acesso em: 04 ago. 2016. 
EI DIN, H. S. et al. Principles of urban quality of life for a neighborhood. HBRC Journal, v. 9, n. 1, p. 86-92, 2013.

ESTÊVES, L. F.; NUCCI, J. C. A questão ecológica urbana e qualidade ambiental urbana. Revista Geografar. Curitiba, v. 10, n.1, p. 26-49, 2015.

FAISAL, K.; SHAKER, A. Improving the accuracy of urban environmental quality assessment using geographically weighted regression techniques. Sensors. Basel, v. 17, n. 3, p. 528, 2017.

FERNANDES, R.D.S. et al. Avaliação da percepção ambiental da sociedade frente ao conhecimento da legislação ambiental básica. Direito, Estado e Sociedade. Rio de Janeiro, v. 1, n. 33, p. 149-160, 2008.

FERREIRA, A. B. D. H. Dicionário da língua portuguesa. 5. ed. Curitiba: Positivo, 2010.

FERREIRA, H. S. Redação de trabalhos acadêmicos: nas áreas das ciências biológicas e da saúde, Rio de Janeiro: Rubio, 2011.

GARAU, C.; PAVAN, V.M. Evaluating Urban Quality: indicator and assessment tools for smart sustainable cities. Sustainability. [S.I.], v. 10, n. 3, p. 575, 2018.

GUEDES, G. R.; NAWROTZKI, R.; CARMO, R. L. D. Percepción y preocupación ambiental en distintas regiones metropolitanas del Brasil: eslabones perdidos y evidencia adicional. Notas de Población. Santiago de Chile, n. 99, p. 133-175, 2014.

HARVEY, D. The Right to the City. New left review. London, n. 54, p. 23-40, 2008.

HOUAISS, A. Grande dicionário Houaiss da língua portuguesa. Rio de janeiro: Objetiva, 2001. $3008 \mathrm{p}$.

IBGE. Instituto Brasileiro de Geografia e Estatística. Pesquisa de Informações Básicas municipais. Perfil dos municípios Brasileiros. Rio de Janeiro: IBGE, 2001. 
IBGE. Instituto Brasileiro de Geografia e Estatística. Sinopse do Censo Demográfico 2010.

Disponível

em:

http://www.censo2010.ibge.gov.br/sinopse/index.php?dados=8 >. Acesso em: $10 \mathrm{abr}$. 2016.

IBGE. Instituto Brasileiro de Geografia e Estatística. Indicadores sociais mínimos conceitos. 2016a.

Disponível

em:

<http://www.ibge.gov.br/home/estatistica/populacao/condicaodevida/indicadoresmini mos/conceitos.shtm>. Acesso em: 12 abr. 2016.

IBGE. Instituto Brasileiro de Geografia e Estatística. IBGE Cidades-Altamira. 2016b. Disponível em: < http://cidades.ibge.gov.br/xtras/perfil.php?codmun=150060>. Acesso em: 12 abr. 2016.

IDESP. Instituto de Desenvolvimento Econômico, Social e Ambiental do Pará. Estatística municipal de Altamira. 2014.

ITB. Instituto Trata Brasil. Esgotamento sanitário inadequado e impactos na saúde da população no período 2008-2011. 2016. Disponível em: < http://www.tratabrasil.org.br/datafiles/uploads/drsai/Book-Trata-B.pdf>. Acesso em: 27 out. 2016.

KRAN, F.; FERREIRA, F. P. M. Qualidade de vida na cidade de Palmas - TO: uma análise através de indicadores habitacionais e ambientais urbanos. Ambiente \& Sociedade. Campinas, v. 9, n. 2, p. 123-141, 2006.

\section{LERMEN, H. S. Percepção ambiental dos moradores da vila parque Santa Anita}

- Porto Alegre. 2008. 63 f. Monografia (Especialização em Saúde Pública), Universidade Federal do Rio Grande do Sul, Porto Alegre, 2008.

LIMA, V. Análise da qualidade ambiental urbana: o exemplo de Osvaldo Cruz/SP. Geografia em questão. Paraná, v. 7, n.2, p. 29-46, 2014. 
LISBOA, S. S.; HELLER, L.; SILVEIRA, R. B. Desafios do planejamento municipal de saneamento básico em municípios de pequeno porte: a percepção dos gestores. Engenharia Sanitária e Ambiental. Rio de janeiro, v. 18, n. 4, p. 341-348, 2013.

LOBO, M.A.A.; TOURINHO, H. K. Z.; COSTA, E. F.N.D. Urbanização, dispersão urbana e estrutura intraurbana de ciudades intermediárias da Amazônia: o caso de Altamira (PA). Boletim de Geografia. Maringá, v. 35, n. 1, p. 43-63, 2017.

LOMBARDO, M. A. Ilha de calor nas metrópoles: o exemplo de São Paulo. São Paulo: Hucitec, 224 p, 1985.

LUENGO, G. Elementos para la definición y evaluación de la calidad ambiental urbana. Una propuesta teórico-metodológica. In: IV SEMINARIO LATINOAMERICANO DE CALIDAD DE VIDA URBANA, 1998, Tandil. Anais...Tandil: 1998.

MACIEL, A. B. C.; FELIPE, J. A.; LIMA, Z. M. C. Os problemas de saneamento e seus impactos sobre a saúde pública do município de Dona Inês/PB. Revista OKARA: Geografia em debate. João Pessoa, v. 9, n.3, p. 524-541, 2015.

MARICATO, E. Informalidade Urbana no Brasil: a lógica da cidade fraturada In: WANDERLEY, L.E; RAICHELIS, R. (org.). A cidade de São Paulo: relações internacionais e gestão pública. São Paulo: EDUC PUC-SP, p. 269-292. 2009.

MARTINS, W. A. et al. Análise da concepção da população do município de PombalPB, sobre o adequado gerenciamento dos resíduos sólidos. Revista Verde de Agroecologia e Desenvolvimento Sustentável. Pombal, v. 9, n. 2, p. 307-316, 2014.

MMA. Ministério do Meio Ambiente. Indicadores Ambientais. 2016. Disponível em: $<$ http://www.mma.gov.br/governanca-ambiental/informacao-ambiental/sistemanacional-de-informacao-sobre-meio-ambiente-sinima/indicadores>. Acesso em: 11 jul. 2016. 
MORSE, S. Indices and indicators in development: An unhealthy obsession with numbers. Routledge, 2004.

MOURA, A, R, D.; NUCCI, J.C. Cobertura vegetal em áreas urbanas - o caso do bairro de Santa Felicidade - Curitiba - PR. Geografia, Ensino \& Pesquisa. Santa Maria, v. 12, n. 1, p. 1682-1698, 2008.

MUCELIN, C.A.; BELLINI, M. Estudo da percepção em ecossistema urbano: uma contribuição para a educação, planejamento e gestão ambiental. Revista Brasileira de Estudos Pedagógicos. Brasília, v. 89, n. 221, p- 119-144, 2008.

NGO, N. S.; KOKOYO, S.; KLOPP, J. Why participation matters for air quality studies: risk perceptions, understandings of air pollution and mobilization in a poor neighborhood in Nairobi, Kenya. Public Health. London, v. 142, p. 177-185, 2017.

NIKOLOPOULOU, M. et.al. Pedestrians' perception of environmental stimuli through field surveys: Focus on particulate pollution. Science of The Total Environment. Amsterdam, v.409, n.13, p. 2493-2502, 2011.

NUCCI, J. C. Qualidade ambiental e adensamento urbano: um estudo de ecologia e planejamento da paisagem aplicado ao distrito de Santa Cecília (MSP). 2 ed. Curitiba: o Autor, 2008.

OKE, T. R. City size and the urban heat Island. Atmospheric Environment Pergamon Press, v. 7 p. 769 - 779. 1973.

ORTEGA, M. V.; DÍAZ, M. M. C.; LOZANO, J. J. M. Percepciones y características del espacio público y ambiente urbano entre habitantes de la ciudad de Cúcuta-Colombia. Prospectiva - Revista de Trabajo Social e Intervención Social. [S.I], n. 21, p. 213239, 2016.

REGO, R.F. et al. Environmental indicators of intra-urban hetererogenety. Cadernos de Saúde Pública. Rio de Janeiro, v. 29, n. 6, p. 1773-1885, 2013. 
RODRIGUES, M. L. et al. A percepção ambiental como instrumento de apoio na gestão e na formulação de políticas públicas ambientais. Saúde e Sociedade. São Paulo, v. 21, n. 3, p. 96- 110, 2012.

ROSSI, U. Cities in global capitalism. Cambridge, UK; Malden, MA: Polity Press, 2017.

SANTOS, C. D. D. A formação e produção do espaço urbano: discussões preliminares acerca da importância das cidades médias para o crescimento da rede urbana brasileira. Revista brasileira de gestão e desenvolvimento regional. Taubaté, v. 5, n.1, p. 177-190, 2009.

SANTOS, F. P. D.; SOUZA, L. B. Percepção da qualidade ambiental urbana dos moradores do bairro Jardim das Oliveiras em Luís Eduardo Magalhães - BA. Interface. Porto Nacional, n.6, p.110-117, 2013.

SANTOS, F. P. D.; SOUZA, L. B. Percepção da qualidade ambiental urbana no bairro Santa Cruz em Luís Eduardo Magalhães (BA). Ateliê Geográfico. Goiânia, v. 8, n.2, p. 168-197, 2014.

SICHE, R. et al. Índices versus indicadores: precisões conceituais na discussão da sustentabilidade de países. Ambiente \& Sociedade. Campinas, v. 10, n. 2, p 137148, 2007.

STREIMIKIENE, D. Comparative assessment of environmental indicators of quality of life in Romania and Lithuania. Economics \& Sociology. [S.I.], v. 7, n. 1, p. 11, 2014.

STREZOV, V.; EVANS, A; EVANS, T. J. Assessment of the Economic, Social and Environmental Dimensions of the Indicators for Sustainable Development. Sustainable Development. [S.I.], v. 25, n. 3, p. 242-253, 2017.

TRINDADE JÚNIOR, S-C.C.D. Pensando a modernização do território e a urbanização 
difusa na Amazônia. Mercator. Fortaleza, v. 14, n. 4, p. 93-106, 2015.

UMBUZEIRO, A.U.B; UMBUZEIRO, U.M. Altamira e sua História. 4ํe ed. Belém: Ponto Press, 2012.

VAZ, J. Medindo a Qualidade de Vida. In: PAULICS, V. et al. (Org). Iniciativas municipais para o desenvolvimento sustentável. Teresina: PCPR, 2002. Disponível

em:<https://books.google.com.br/books?id=600qAAAAYAAJ\&printsec=frontcover\&hl $=p t-B R \# v=o n e p a g e \& q \& f=f a l s e>$. Acesso em: 03 jul. 2016.

VIEIRA, J. D. et al. A urbanização no mundo e no Brasil sob um enfoque geográfico. Ciências Humanas e Sociais. Aracajú, v.3, n.1, p. 95-106, $2015 a$.

VIEIRA, J. D. et al. Uma breve história sobre o surgimento e desenvolvimento do capitalismo. Ciências Humanas e Sociais. Aracajú, v.2, n.3, p. 125-137, 2015b.

4. Para esse trabalho, a cobertura vegetal refere-se a qualquer área provida de vegetação no bairro, compreendendo a vegetação herbácea, arbustiva e arbórea.

Enviado: Outubro, 2019.

Aprovado: Outubro, 2019. 